\title{
The diversity among the species Tetragenococcus halophilus including new isolates from a lupine seed fermentation
}

\author{
Tobias Link@i), Rudi F. Vogel[1] and Matthias A. Ehrmann*
}

\begin{abstract}
Background: Tetragenococcus (T.) halophilus can be isolated from a variety of fermented foods, such as soy sauce, different soy pastes, salted fish sauce and from cheese brine or degraded sugar beet thick juice. This species contributes by the formation of short chain acids to the flavor of the product. Recently, T. halophilus has been identified as a dominant species in a seasoning sauce fermentation based on koji made with lupine seeds.

Results: In this study we characterized six strains of T. halophilus isolated from lupine moromi fermentations in terms of their adaptation towards this fermentation environment, salt tolerance and production of biogenic amines. Phylogenic and genomic analysis revealed three distinctive lineages within the species T. halophilus with no relation to their isolation source, besides the lineage of T. halophilus subsp. flandriensis. All isolated strains from lupine moromi belong to one lineage in that any of the type strains are absent. The strains form lupine moromi could not convincingly be assigned to one of the current subspecies. Taken together with strain specific differences in the carbohydrate metabolism (arabinose, mannitol, melibiose, gluconate, galactonate) and amino acid degradation pathways such as arginine deiminase pathway (ADI) and the agmatine deiminase pathway (AgDI) the biodiversity in the species of T. halophilus is greater than expected. Among the new strains, some strains have a favorable combination of traits wanted in a starter culture.

Conclusions: Our study characterized T. halophilus strains that were isolated from lupine fermentation. The lupine moromi environment appears to select strains with specific traits as all of the strains are phylogenetically closely related, which potentially can be used as a starter culture for lupine moromi. We also found that the strains can be clearly distinguished phylogenetically and phenotypically from the type strains of both subspecies T. halophilus subsp. halophilus and T. halophilus subsp. flandriensis.
\end{abstract}

Keywords: Lupine moromi, Tetragenococcus halophilus, Starter culture, Phylogenetic lineages

\section{Introduction}

The genus Tetragenococcus (T.) currently comprises five different species including T. osmophilus, T. muriaticus, T. solitarius, T. koreensis and T. halophilus with the two subspecies $T$. halophilus subsp. halophilus and $T$. halophilus subsp. flandriensis [1-5]. Tetragenococci are

*Correspondence: matthias.ehrmann@tum.de

Lehrstuhl für Mikrobiologie, Technische Universität München,

85354 Freising, Germany
Gram-positive, non-motile, facultative anaerobic lactic acid bacteria adapted to high sugar or high salinity habitats. T. halophilus is characterized by its high $\mathrm{NaCl}$ tolerance up to $20 \%$, growth at $\mathrm{pH} 7-9$, but a moderate acid tolerance below pH 5 [6-8]. Thus, T. halophilus strains are typically isolated from fermented foods containing high amounts of $\mathrm{NaCl}$ such as soy sauce moromi, soy pastes or different variants of fermented fish products [9-11]. This species contributes to the fermentation by the production of organic acids as well as the degradation 
of unfavoured sugars [12-14]. Moreover, T. halophilus strains are able to prevent the growth of different autochthonous strains harboring the potential to produce biogenic amine (BA) and thereby reduce the BA content in the final product [15]. For some strains a degradation of aflatoxins is reported [16]. The ability of T. halophilus to survive in high saline environments is mainly due to the import of compatible solutes such as glycine betaine, proline and choline via the OpuA, OpuC, OpuD and Bet $T$ transporters as the intracellular accumulation of glycine betaine and proline is favored under high saline conditions [17-20]. Besides the import of these compatible solutes the ADI pathway is also upregulated under high saline conditions generating ammonia and increasing the intracellular citrulline content [21]. Under saline conditions the glutamate dehydrogenase as well as the $\mathrm{Na}^{+}$translocating V-Type ATPase were also more abundant [22].

Although the majority of isolates come from high salt soy and fish fermentations, there are also more recent reports on isolates from degraded sugar beet thick juice, Brie de meaux cheese rind, mountain snow and from water samples [5, 23-25].

This study reports on the characterization of previously isolated T. halophilus strains occurring in a seasoning sauce fermentation based on koji made from lupine seeds [41]. We investigated these strains to see whether and to what extent the use of the hitherto uncommon substrate lupine selects for specifically adapted isolates and propose traits, which useful in the selection of starter cultures. To reveal genomic differences within the species we used a comparative genomics approach supported by physiological data. Furthermore, we characterized the new strains with regards to their salt tolerance, formation of biogenic amines, carbohydrate metabolism and bacteriocin production.

\section{Results}

\section{Genomic diversity of Tetragenococcus halophilus}

The genomes of six isolates from lupine moromi as well as from DSM 20337 were sequenced. The genome sequences of the isolates from lupine moromi were compared to previously published genomes available in a public database (NCBI). In order to avoid using sequences that are identical we set an ANIb (average nucleotide indices based on Blast) value cutoff of $99.6 \%$ for the selection of strains from the NCBI database (Table 1). To further ensure that the set of strains used was representative for the species a pan/core plot was generated (Fig. S1). As the number of genes included in the core genome only slightly decreased after seventeen strains the core genome was considered as closed. The genome sizes of T. halophilus strains ranges from 2.26 to
2.6 $\mathrm{Mb}$ and the GC content ranges from 35.55 to $36.32 \%$ (Table 1). Member of this species only sporadically carry plasmids as the type strain T. halophilus subsp. flandriensis DSM $23766^{\mathrm{T}}$ is carrying one plasmid and the strains TMW 2.2256, TMW 2.2257 and TMW 2.2263 are predicted to carry a plasmid as it can be derived from the genomic sequences.

Sequence similarity of $16 \mathrm{~S}$ rRNA genes and of concatenated housekeeping genes, the ANIb values and the in-silico DDH (DNA-DNA hybridization) values were calculated and used to define the genomic relationship of the strains to each other. The phylogenetic tree from the alignment of the $16 \mathrm{~S}$ rRNA gene revealed that all of the isolates from lupine moromi are belonging to the species T. halophilus (Fig. S2). To further analyze the phylogenetic relatedness, seven marker genes (fus $A, \operatorname{gyr} A$, gyrB, lepA, pyrG, recA, rpoD) were used to construct phylogenetic trees (Fig. 1 and Fig. S3). This revealed three distinctive lineages within the T. halophilus species. The first includes 13 strains from varying origin, all strains isolated from lupine moromi were present within this lineage. The second lineage includes 11 strains and the type strain T. halophilus subsp. halophilus DSM $20339^{\mathrm{T}}$. The third lineage consisted only of the type strain T. halophilus subsp. flandriensis DSM $23766^{\mathrm{T}}$. This separation into these three lineages is also supported by the ANIb values. With the first lineage being the most divers one with a median ANIb value of 97.4. The second lineage is more alike with an intra-lineage median ANIb value of 98.4. The inter-lineage median ANIb value when comparing lineage I vs. lineage II is 96.8 . These values support the separation of both lineages but still do not allow a separation into two subspecies. In order to further determine the subspecies affiliation of our isolates the genomic distance of the type strains T. halophilus subsp. halophilus DSM $20339^{\mathrm{T}}$ and T. halophilus subsp. flandriensis DSM $23766^{\mathrm{T}}$ was calculated using the GGDC 2.1 calculator. The in-silico DDH values of all of the new isolates from lupine moromi were $<79 \%$ when compared to the type strain DSM $20339^{\mathrm{T}}$ or to DSM $23766^{\mathrm{T}}$.

Comparative analysis for CDS only present in either lineage revealed no specific CDS for lineage I could be found that is present in all strains, but in eleven of thirteen strains a PTS IIC component, a LacI regulator and an alpha-L-fucosidase are present. Besides that, in another constellation of eleven strains from lineage I a fumarate reductase subunit, a hypothetical protein and a subunit opuAC are present, which are absent in strains from lineage II (Table S2).

As the total number specific CDS for lineage II is lower compared to lineage I, lineage II appears to be more homogenous. Ten CDS could be found that are unique to lineage II. Among these, the most interesting CDS is the 
Table 1 Strains used, accession numbers and characteristics of their genomes

\begin{tabular}{|c|c|c|c|c|c|c|c|}
\hline Accession number & Strain name & References & Origin & Genomsize (bp) & Contigs & Plasmids & $\mathrm{G} / \mathrm{C}$ content $(\%)$ \\
\hline СР027783 (1-3) & $\begin{array}{l}\text { T. osmophilus DSM } \\
23765^{\top}\end{array}$ & Juste et al., 2012 & $\begin{array}{l}\text { Degraded sugar thick } \\
\text { juice }\end{array}$ & 2329167 & 3 & 2 & 36.34 \\
\hline СР027768 (1-2) & $\begin{array}{l}\text { T. halophilus subsp. } \\
\text { flandriensis DSM } \\
23766^{\top}\end{array}$ & Juste et al., 2012 & $\begin{array}{l}\text { Degraded sugar thick } \\
\text { juice }\end{array}$ & 2724800 & 2 & 1 & 36.32 \\
\hline NZ_PXYA01000000 & $\begin{array}{l}\text { T. halophilus subsp. } \\
\text { halophilus DSM } \\
20339^{\top}\end{array}$ & Chun et al., 2019 & Salted anchovy & 2595756 & 5 & & 36.03 \\
\hline NC_016052 & $\begin{array}{l}\text { T. halophilus subsp. } \\
\text { halophilus NBRC } \\
12172\end{array}$ & NITE 2011 & Soy sauce mash & 2562720 & 1 & & 36.04 \\
\hline СР012047 & T. halophilus MJ4 & Kim et al., 2019 & Fish (anchovy) sauce & 2389470 & 1 & & 35.99 \\
\hline CP046246 & T. halophilus YJ1 & Yonsei University & Salty fish sauce & 2476596 & 1 & & 36.12 \\
\hline CP020017 & T. halophilus KUD23 & Lee et al., 2018 & $\begin{array}{l}\text { Korean soypaste } \\
\text { doenjang }\end{array}$ & 2599117 & 1 & & 36.06 \\
\hline NZ_LSFG00000000 & T. halophilus FBL3 & Kim et al., 2017 & Galchijeot, fish sauce & 2420904 & 87 & & 35.75 \\
\hline BLRM01000000 & T. halophilus WJ7 & Shirakawa et al., 2020 & $\begin{array}{l}\text { Fish nukazuke with } \\
\text { rice bran }\end{array}$ & 2443531 & 113 & & 35.56 \\
\hline JACABZ000000000 & $\begin{array}{l}\text { T. halophilus TMW } \\
2.2254\end{array}$ & This study & Lupine moromi & 2401046 & 77 & & 35.7 \\
\hline JACACA000000000 & $\begin{array}{l}\text { T. halophilus TMW } \\
2.2256\end{array}$ & This study & Lupine moromi & 2407620 & 101 & 1 & 35.73 \\
\hline JACACB000000000 & $\begin{array}{l}\text { T. halophilus TMW } \\
2.2257\end{array}$ & This study & Lupine moromi & 2483454 & 92 & 1 & 35.69 \\
\hline JACACH000000000 & $\begin{array}{l}\text { T. halophilus TMW } \\
2.2263\end{array}$ & This study & Lupine moromi & 2459525 & 98 & 1 & 35.74 \\
\hline JACACI000000000 & $\begin{array}{l}\text { T. halophilus TMW } \\
2.2264\end{array}$ & This study & Lupine moromi & 2308230 & 76 & & 35.7 \\
\hline JACACK000000000 & $\begin{array}{l}\text { T. halophilus TMW } \\
2.2266\end{array}$ & This study & Lupine moromi & 2388983 & 97 & & 35.78 \\
\hline JACTUX000000000 & $\begin{array}{l}\text { T. halophilus subsp. } \\
\text { halophilus DSM } 20337\end{array}$ & This study & Soy sauce mash & 2259739 & 112 & & 35.67 \\
\hline NZ_BDDZ00000000 & $\begin{array}{l}\text { T. halophilus subsp. } \\
\text { halophilus } 11\end{array}$ & Nishimura et al., 2017 & Soy sauce mash & 2410712 & 311 & & 35.55 \\
\hline NZ_BDEH00000000 & $\begin{array}{l}\text { T. halophilus subsp. } \\
\text { halophilus D10 }\end{array}$ & Nishimura et al., 2017 & Soy sauce mash & 2438535 & 259 & & 35.63 \\
\hline NZ_BDEI000000000 & $\begin{array}{l}\text { T. halophilus subsp. } \\
\text { halophilus D- } 86\end{array}$ & Nishimura et al., 2017 & Soy sauce mash & 2455970 & 315 & & 35.61 \\
\hline NZ_BDEC00000000 & $\begin{array}{l}\text { T. halophilus subsp. } \\
\text { halophilus NISL } 7118\end{array}$ & Nishimura et al., 2017 & Soy sauce mash & 2401304 & 281 & & 35.72 \\
\hline NZ_BDEF00000000 & $\begin{array}{l}\text { T. halophilus subsp. } \\
\text { halophilus NISL } 7126\end{array}$ & Nishimura et al., 2017 & Soy sauce mash & 2511812 & 214 & & 35.71 \\
\hline JABEVO010000000 & T. halophilus KG12 & & Korean soy sauce & 2515188 & 117 & & 35.69 \\
\hline BLRP01000000 & T. halophilus YG2 & Shirakawa et al., 2020 & Soy sauce mash & 2372244 & 117 & & 35.67 \\
\hline BLRO01000000 & T. halophilus YA5 & Wakinaka et al., 2019 & Soy sauce mash & 2318625 & 122 & & 35.72 \\
\hline BLRN01000000 & T. halophilus YA163 & Shirakawa et al., 2020 & Soy sauce mash & 2420090 & 132 & & 35.7 \\
\hline BKBL01000000 & T. halophilus 8C7 & Unno et al., 2020 & $\begin{array}{l}\text { Brie de meaux cheese } \\
\text { rind }\end{array}$ & 2344983 & 132 & & 35.85 \\
\hline
\end{tabular}

hsp33 family molecular chaperone HslO. Although not present in all strains form lineage II, it is notable that a putative glycerol sn-3- phosphate transporter and a putative pentose $\mathrm{ABC}$ transporter $x y l E F G$ are present only in the strains from lineage II (Table S2).

\section{Analysis of carbohydrate metabolism}

As utilization of available carbohydrates is essential for the growth and is the main way of T. halophilus for generation of ATP, the carbohydrate metabolisms can be quite diverse depending on the isolation source $[6$, 


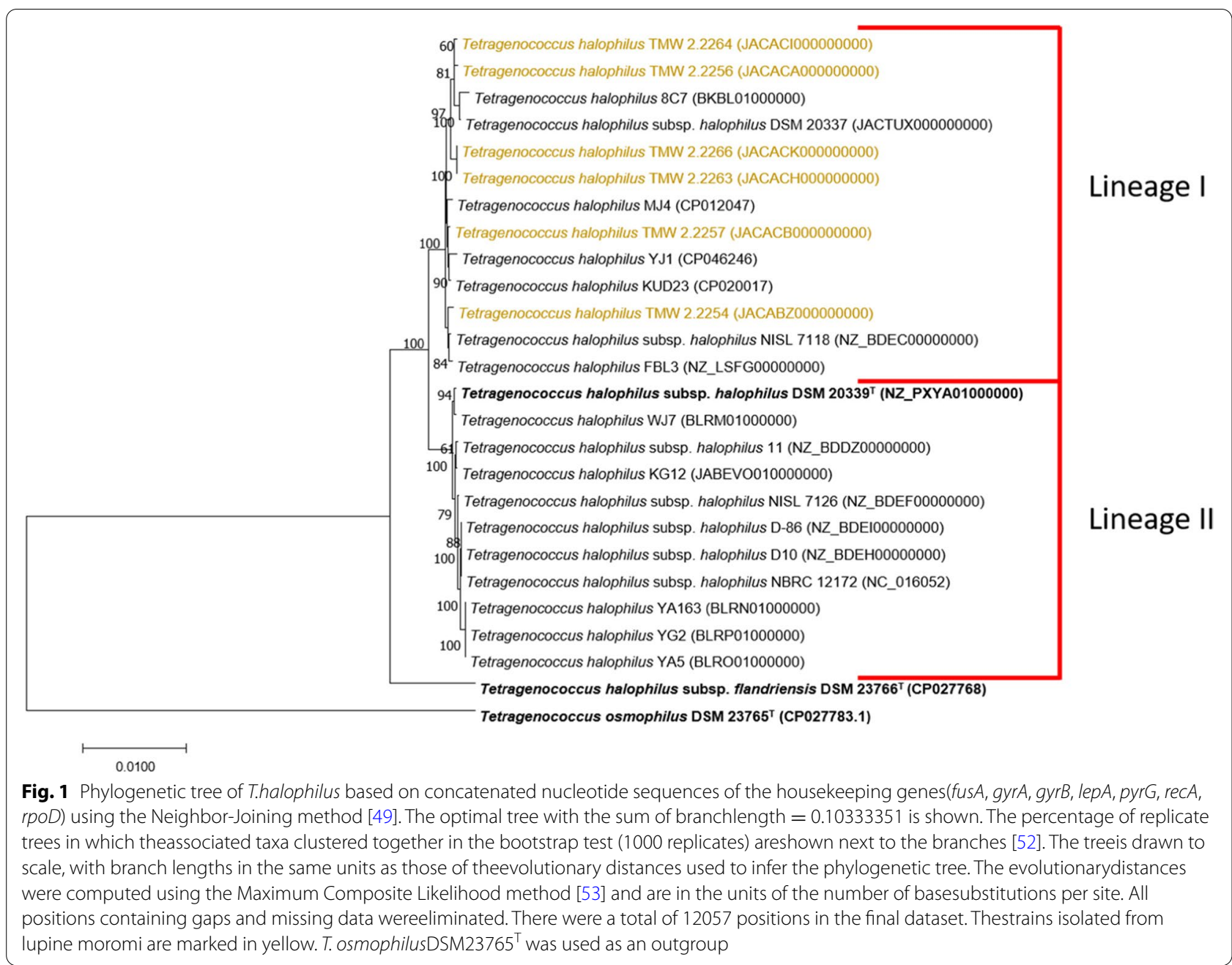

10, 26-29]. We therefore looked at the carbohydrate metabolism of each strain. Using BADGE variations in the abundance of the carbohydrate metabolizing cluster L-arabinose, D-ribose, D-xylose, D-galactose, D-lactose, D-melibiose, D-mannitol, D-sorbitol, gluconate and galactonate were found in most of the strains of the set used in this study. Functional metabolic cluster prediction based on the NCBI, RAST, TIGR and KEGG annotations were analyzed for the entire set and clustered using Perseus (Fig. 3). There are no specific traits referring to the new substrate, which is lupine moromi, as the only metabolic clusters all isolates from lupine moromi have in common are the ones for D-ribose, D-galactose and D-mannitol. The cluster for the metabolism of D-ribose and D-galactose appears to be conserved in the species T. halophilus, all other metabolic clusters are strain-dependent features. However, a higher occurrence of L-arabinose cluster araBDAER can be seen in isolates from lineage II (Fig. 3).
We found that for all strains isolated from lupine moromi and DSM strains the genomic prediction of functional metabolic cluster were correct besides for the metabolism of gluconate as no one the strains tested in the API test showed production of acid from gluconate (Table 2).

\section{Amino acid metabolism and osmotolerance mechanisms}

Variations in several amino acid degradation pathways contributing towards $\mathrm{pH}$ homeostasis and osmotolerance are present in the strains isolated from lupine moromi as well as in the rest of the set used. The major degradation pathway for arginine via the arginine deiminase (ADI) pathway encoded by $\operatorname{argRRABC}$ and $\operatorname{arcCRD}$ is strain dependent. Some of the strains have a disrupted operon or are missing several genes of the ADI pathway leading towards an inactive pathway [30]. Among the strains isolated from lupine moromi the strains TMW 2.2254, TMW 2.2263 and TMW 2.2266 have an incomplete ADI 

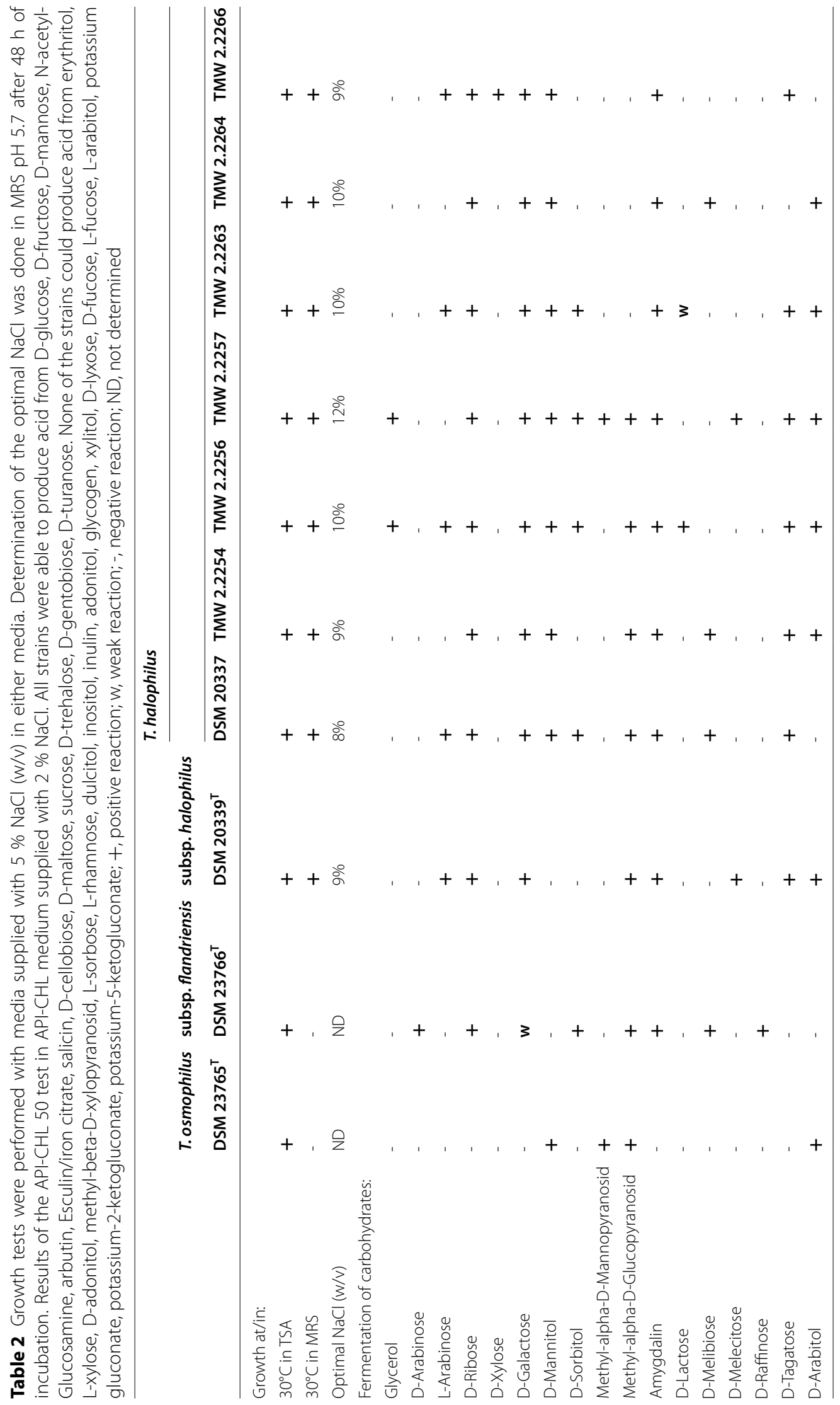
pathway due to absence of the second $\arg R$ regulator, the genes $\arg B$ and $\arg C$ and the transporter with respective regulator $\operatorname{arcCRD}$. Similar incomplete ADI pathways can be found in the strains DSM $23766^{\mathrm{T}}, \mathrm{D} 10, \mathrm{D}-86, \mathrm{WJ}$, NISL 7118 and 8C7. Indicating that a different pathway might compensate the loss of the ADI pathway.

The ability to decarboxylate aspartate via the aspartate decarboxylase ( $a s p D$, EC:4.1.1.12) is only present in the strains D10, D-86, NBRC 12172, NISL 7126, YA163, YG2, DSM $20339^{\mathrm{T}}$, KUD23, TMW 2.2254 and TMW 2.2264. In the strain YA5 this decarboxylase seems to be frameshifted due to premature stop codon. The aspartate/alanine antiporter $(a s p T)$ is adjacent to the decarboxylase in all of these strains.

The ornithine cyclodeaminase (odc, EC:4.3.1.12) is present in all strains but in strain FBL3. In DSM 20337, D10 and D-86 the orf is splitted due to the end of a contig. The orf in the type strain DSM $20339^{\mathrm{T}}$ is disrupted due to insertion of a transposase and is probably not functional.

The import of compatibles solutes in T. halophilus is mediated by the opuA, ориC, bus $A B$, ори $A B C$ systems and the bcct transporter betT. The busAB and opuC systems are present in all strains. The orfs for the opuAA subunit of opuABC transporter in strain $8 \mathrm{C} 7$ are frameshifted due to a premature stop codon. The strain TMW 2.2266 did not harbor the complete opuA system putatively transporting glycine betaine and proline. The betaine-aldehyde dehydrogenase ( $g b s A, \mathrm{EC}: 1.2 .1 .8$ ), the choline dehydrogenase (gbsB, EC:1.1.1.1) and the HTHtype regulator $g b s R$ are present in all strains but TMW 2.2266 .

Genome analysis of the entire set for histidine (BAG14318.1, BAG14319.1) and tyrosine (WP_031944088.1) decarboxylases reveals that only $T$. halophilus subsp. halophilus 11 encodes for a histidine decarboxylase. None of the TMW strains produces any biogenic amines from histidine or tyrosine. Furthermore, using multiple annotation pipelines (NCBI, RAST, TIGR) a cluster consisting of four genes related to the agmatine deiminase pathway (agDI) was found in the strains D10, D-86, WJ7, KUD23 and TMW 2.2266. The cluster encodes an agmatine deiminase, a putrescine carbamoyl transferase, a LacI regulator and an amino acid permease.

\section{Bacteriophages and CRISPR/Cas systems in Tetragenococcus halophilus}

Using Phaster "intact" bacteriophages in the genomes of DSM $23766^{\mathrm{T}}$, KG12, NISL 7126, NBRC 12172, YA163, FBL3, TMW 2.2254, TMW 2.2256, TMW 2.2257, TMW 2.2263, TMW 2.2264 and TMW 2.2266 were identified. The program also correctly predicted the phage of the strain D-86 [31]. However, the phage of D10 was only predicted as questionable with a score of 80 . A score of
90 would be considered as intact, this can be due to the sequence quality as the phage was shown to be lytic [32].

CRISPR/Cas systems are part of the defense against bacteriophages and foreign DNA. Nine different Cas type combinations with an evidence level of 4 were identified in 12 strains of T. halophilus. Two strain had an evidence level of 1 . In 11 strains no marker proteins of a specific Cas type or with an evidence level of 0 were identified. Manual screening of Cas marker genes revealed that only in strains with an evidence level of 4, Cas proteins are present. The type of Cas systems does not correlate with any isolation source nor with the absence or presence of bacteriophages (Table S1).

\section{Bacteriocin production}

Bacteriocins can positively contribute to the competitiveness of a strain within a fermentation broth. To identify potential bacteriocin producing strains BAGEL4 was used [33]. BAGEL did not find any orfs related to a Bacteriocins. BAGEL only detected one orf annotated as peptidoglycan DD-metalloendopeptidase in the strains DSM $20339^{\mathrm{T}}, 11,8 \mathrm{C} 7$, NISL 7118, D-86, YA5, WJ7, YA163 and DSM 20337 has a $42-45 \%$ (AA) similarity to a Zoocin A, a peptidoglycan hydrolase produced by Streptococcus equi.

\section{Discussion}

In this study we characterized and compared T. halophilus strain isolated from lupine moromi with strains from different environment, in order to identify traits that might be necessary or wanted in a starter culture for the lupine moromi fermentation. Therefore, we compared these strains in terms of their salt tolerance, formation of biogenic amines, carbohydrate metabolism, potential bacteriocin production and the identified Cas systems.

Strains isolated from lupine moromi were compared to a representative set of publicly available genomes sequences from T. halophilus (Table 1) (Fig. S1). The $16 \mathrm{~S}$ rRNA gene similarity $\geq 98.7 \%$ with both subspecies type strains, DSM $20339^{\mathrm{T}}$ and DSM $23766^{\mathrm{T}}$, shows that all of the new isolates belong of the species T. halophilus (Fig. S2). Using concatenated housekeeping genes (fusA, gyrA, gyrB, lepA, pyrG, recA, rpoD), two lineages in the species T. halophilus could be revealed (Fig. 1, Fig. S3). All isolates from lupine moromi are all belong to the same lineage (lineage I). However, none of the type strains belong to this lineage. The separation into two lineages is further supported by the ANIb values (Fig. 2). Based on phenotypic (D-arabinose, D-lactose, D-raffinose, glycerol) and genotypic differences observed, as well as the different origins of the strains and the industrial relevance of thick juice degradation, two subspecies $T$. halophilus subsp. halophilus and T. halophilus subsp. flandriensis have 


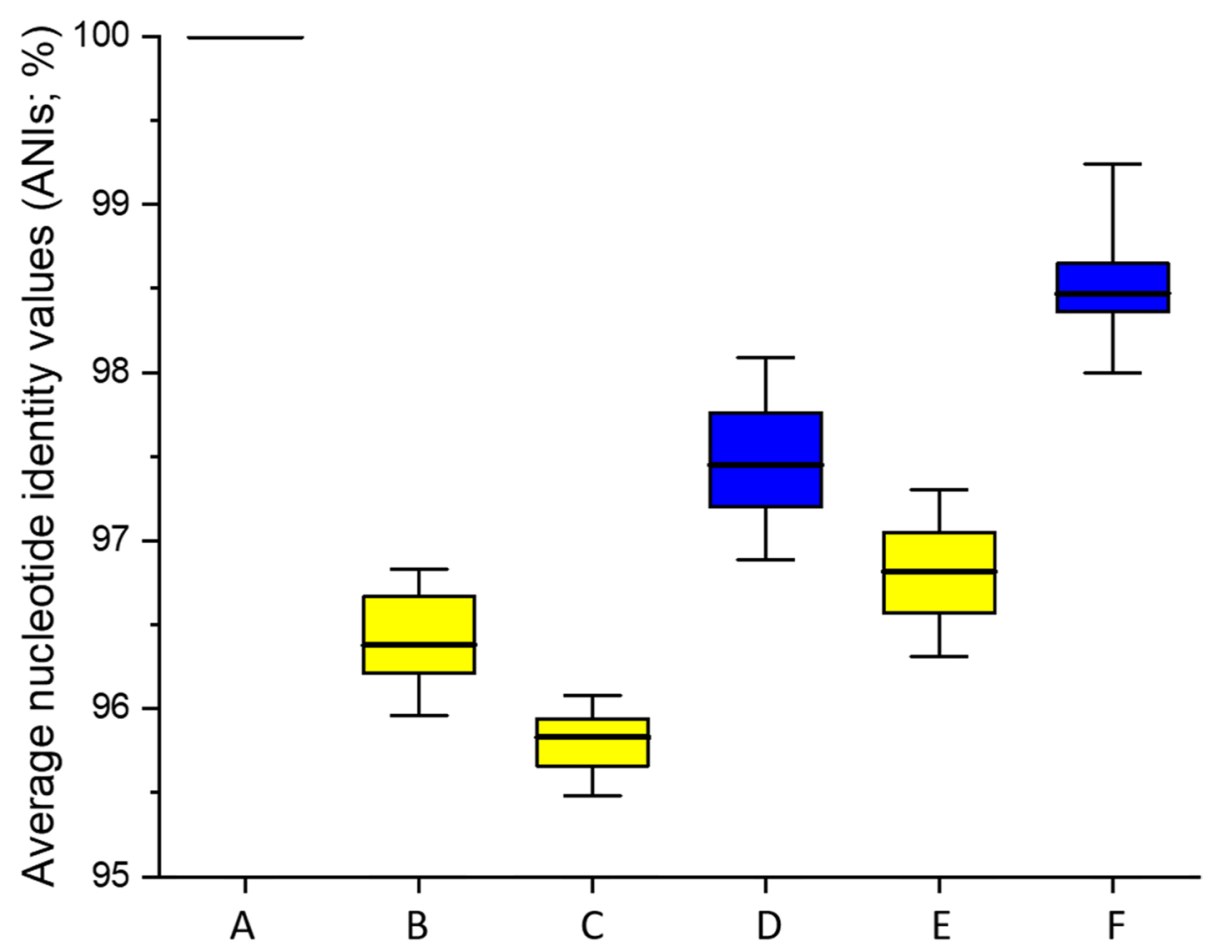

Fig. 2 Pairwise average nucleotide identity values(ANl;\%) of genome sequence belonging to the same lineage of T. halophilus.ANI values were calculated for the strain within the same linage or betweenlineages. A: Intralineage values of T. halophilus subsp. flandriensis, B: Interlineagevalues of T. halophilus subsp. flandriensis to the strains of Lineage I,C: Interlineage values of T. halophilus subsp. flandriensis to the strainsof Lineage II, D: Intralineage values of T. halophilus lineage I, E:Interlineage values of T. halophilus lineage I to lineage II, F:Intralineage values of T. halophilus lineage II

been described previously [5]. Genomic analysis showed that some of the set criteria (e.g. D-lactose) are just strain dependent features, that in fact do not correlate with the subspecies affiliations. The isolates from lupine moromi cannot be clearly assigned towards one of the existing subspecies, based on the requirements for subspecies delineation. Furthermore, a potential third subspecies might be present as the in silico DDH values of the strains from lupine moromi range from $73.1 \%$ to $77.1 \%$ to the type strain of DSM $20339^{\mathrm{T}}$ and $74.5 \%-77 \%$ to the type strain DSM $23766^{\mathrm{T}}$, as in silico DDH $\geq 79 \%$ will be classified as same sub-species [34, 35]. These results indicate the possibility of a third subspecies and also demonstrate that the biodiversity in the species T. halophilus is greater than expected.

The core genome of the species T. halophilus consists of 1200 CDS of the Pan genome in size, this indicates that the species has a high biodiversity. A similar diversity can also be found in other LAB e.g. in Limosilactobacillus reuteri and Lactobacillus delbrueckii, both species with a demonstrated high species diversity and adaptation to different niches [36]. The carbohydrate utilization of several plant-based carbohydrates is conserved in T. halophilus (D-glucose, D-mannose, D-galactose, D-ribose, D-maltose). However, some of the pathways associated with salt tolerance and response salt stress (ADI, AgDI, aspDT) are strain dependent features among all members of the species T. halophilus.

Although soybeans and lupine seeds have comparable nutrient contents, the major difference is in the composition of lupine and soybean galactans. Galactans from soybeans have a higher L-arabinose content than the galactans from lupine seeds [37]. This may be the reason why the distribution of the araBADER operon is higher among strains from soybean fermentations (Fig. 3). Interestingly the distribution of clusters for the utilization of sugar alcohols (D-mannitol, D-sorbitol, gluconate, galactonate) is also the highest among isolates from lupine moromi. Although all the genes for gluconate metabolism are present in the strains- from lupine moromi, none of the strains produced acid from gluconate in the API 50 $\mathrm{CHL}$ test (Table 2). Considering the mechanisms towards $\mathrm{pH}$ homeostasis and amino acid degradation the isolates from lupine moromi do not show a clear adaptation towards a different environment as only strain dependent differences could be found.

To assess the starter culture suitability of the strains from lupine moromi, salt tolerance and formation of biogenic amines were analyzed. None of strains produced any tyramine or histamine in MRS supplied with the 


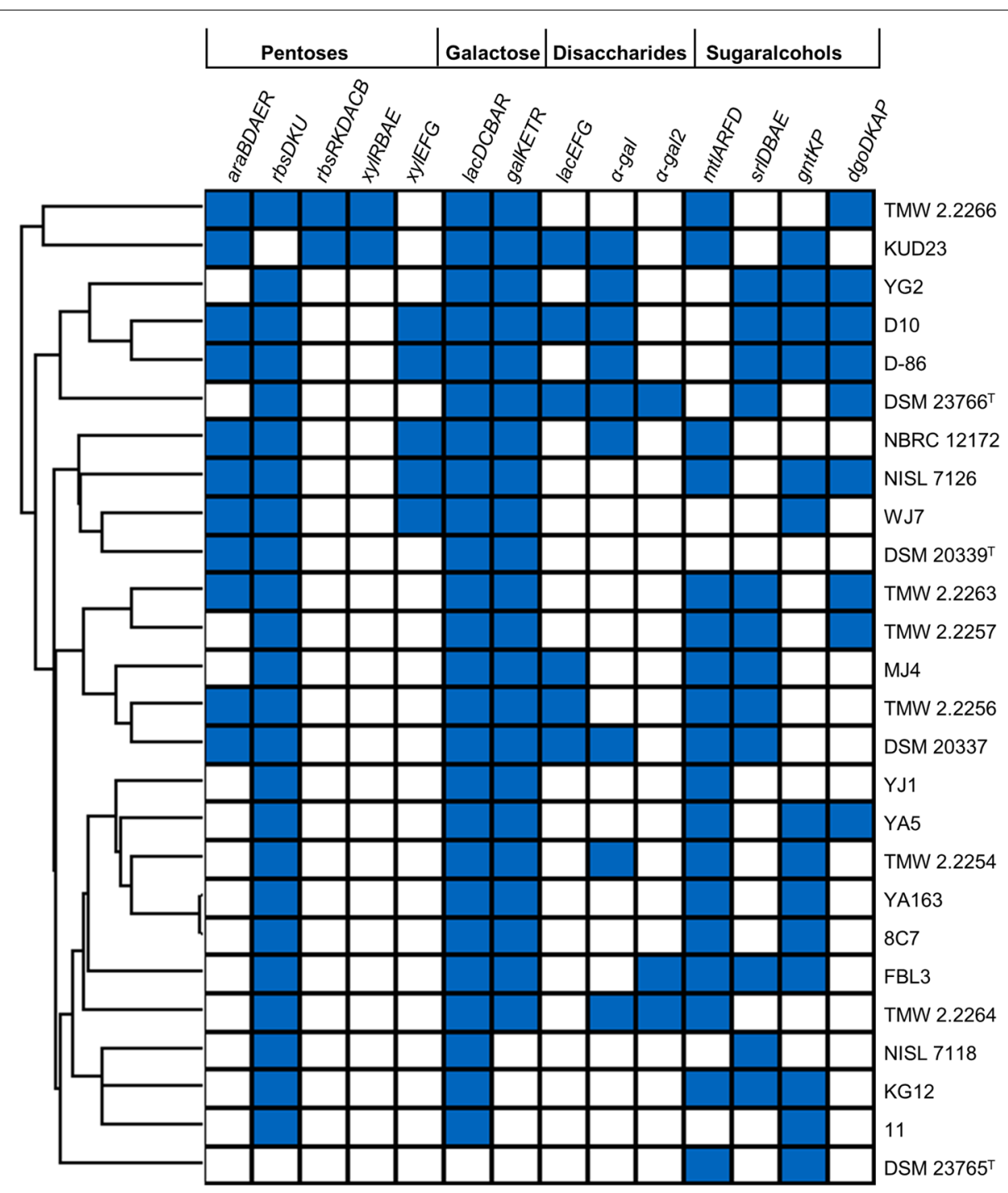

Fig. 3 Hierarchical clustering of the functionalcarbohydrate metabolism cluster in T. halophilus using the hierarchicalclustering function with Euclidean distance clustering in Perseus. Black box=functional and complete cluster. White box= incomplete/unfunctional or missingcluster. The strain T. osmophilus DSM $23765^{\top}$ was used as anoutgroup

respective precursor amino acid. The absence of respective genes encoding decarboxylases was also confirmed by genomic analysis.

As citrulline, an intermediate of the ADI pathway, is associated with the formation of ethyl carbamate during the soy sauce fermentation [38], starter cultures should ideally be ADI negative to avoid the formation and accumulation of citrulline. Three strains from lupine moromi (TMW 2.2254, TMW 2.2263, TMW 2.2266) are ADI negative and could therefore be considered as potential starter strains. However, the strain TMW 2.2266 is AgDI positive and therefore is potentially not safe in terms in biogenic amines formation. Interestingly, strains only posses either a complete ADI or AgDI pathway but not both. Furthermore, the genomic analysis for potential prophages revealed that all of the isolates from lupine moromi had at least one predicted intact prophage. To avoid phage induced lysis of the starter strain and therefore the delay or stop of the directed fermentation as seen in other fermentations [39], a mixture of strains should be considered as starter culture. We could furthermore detect multiple different Cas types in the strains isolated from lupine moromi as well as in other strains from $T$. halophilus. Notably not all $T$. halophilus strains do possess a CRISPR/Cas system with no correlation to their isolation source (Table S1). However, as these are 
strain dependent differences, these could be used for strain identification and typing to track strains during a fermentation, as a similar approach was used in Fructilactobacillus sanfranciscensis [40]. Screening for bacteriocin production cluster of all the lupine moromi isolated strains could not detect any candidate genes. Which suits the strains well for a multi-strain culture and indicates that bacteriocins are not necessary for the domination of microbiota in lupine moromi.

\section{Conclusions}

The phenotypical discrimination between strains from lupine moromi and other isolation sources is still presumably done at the carbohydrate level. The new environment, lupine moromi, selects only for strains from lineage I. Therefore, we proposed only strains from this lineage as potential starters for the lupine moromi fermentation. We could find that some traits and mechanisms associated with salt tolerance (opuA, gbsAB, ADI) are only strain dependent features. Phylogenetic analysis revealed three lineages within the species of $T$. halophilus. This delineation within the species is supported by DDH values $<79 \%$ for most of the strains in lineage I. Despite a given genomic coherency and distinguishability, at the time of writing we do not have sufficient data to provide a strong proposal for a third subspecies including strains of lineage I.

\section{Methods}

\section{Isolation of strains and origin of type strains}

Six new T. halophilus strains were isolated from the moromi fermentation of a novel lupine seed fermentation as described by Lülf et al., [41]. Toasted lupine seeds were soaked in water, cracked, mashed and subsequent fermented at $28-35{ }^{\circ} \mathrm{C}$ for two days with Aspergillus oryzae in an industrial fermentation of the Purvegan factory (Ramsen, Germany). The seeds taken from koji were mixed in the ratio 1:1.5 with tap water containing varying concentrations of $\mathrm{NaCl}$ $(10 \%-20 \%(\mathrm{w} / \mathrm{v}))$ to establish different moromi fermentations [41]. Bacteria were isolated performing a serial dilution of moromi samples with Ringer solution (Merck) and were then streaked out on MRS agar plates with $5 \%(\mathrm{w} / \mathrm{v}) \mathrm{NaCl}$ and $\mathrm{pH}$ adjusted to 5.7 [42]. MRS plates were incubated at $30{ }^{\circ} \mathrm{C}$ for four days in an anaerobic jar with an AnaeroGen ${ }^{\text {TM }}$ sachet (Thermo Scientific, Waltham, MA, USA) to create microaerobic conditions. The strain TMW 2.2254 was isolated from a fermentation with $10 \%(\mathrm{w} / \mathrm{v}) \mathrm{NaCl}$ after eight weeks. TMW 2.2257 was isolated from $13.5 \%(w / v) ~ N a C l$ after
12 weeks and the strain TMW 2.2263 was isolated from $15 \%(\mathrm{w} / \mathrm{v}) \mathrm{NaCl}$ after 12 weeks. Additionally, a second set of fermentations were inoculated with mature moromi from the Purvegan factory, also containing $10 \%-20 \%(\mathrm{w} / \mathrm{v}) \mathrm{NaCl}$. From this second set, the strain TMW 2.2256 was isolated from a fermentation with $10 \%(\mathrm{w} / \mathrm{v}) \mathrm{NaCl}$ after two weeks. TMW 2.2264 was isolated from the inoculated moromi fermentation containing $15 \%(\mathrm{w} / \mathrm{v}) \mathrm{NaCl}$ after two weeks. TMW 2.2266 was isolated from the inoculated moromi containing $15 \%(\mathrm{w} / \mathrm{v}) \mathrm{NaCl}$ after 12 weeks. All isolates were identified via Matrix Assisted Laser Desorption Ionization - Time of Flight (MALDI-ToF) mass spectrometry (Bruker, Billerica, Massachusetts, USA). T. halophilus DSM 20337, T. osmophilus DSM 23765 T. halophilus subsp. flandriensis DSM $23766^{\mathrm{T}}$ and T. halophilus subsp. halophilus DSM $20339^{\mathrm{T}}$ were from DSMZ (Braunschweig, Germany).

\section{Cultivation conditions}

All strains were grown at $30^{\circ} \mathrm{C}$ in a $15 \mathrm{ml}$ or $50 \mathrm{ml}$ closed tubes without shaking in MRS pH 5.7 [42] or TSA (Caso Bouillon) (Carl Roth, Karlsruhe, Germany) containing $5 \% \mathrm{NaCl}(\mathrm{w} / \mathrm{v})$ (Carl Roth, Karlsruhe, Germany).

\section{DNA isolation and Genome sequencing}

Genomic DNA was isolated from bacterial cultures grown in $10 \mathrm{ml}$ MRS containing $5 \%(\mathrm{w} / \mathrm{v}) \mathrm{NaCl}$ using the E.Z.N.A Bacterial DNA-Kit (Omega bio-tek, Norcross, Georgia, USA) according to the manufacturer's instructions. Isolated genomic DNA was sequenced by Eurofins Genomics (Konstanz, Germany) with Illumina HiSeq with the sequence mode NovaSeq 6000 S2 PE150 XP.

\section{Genome analyses}

Assembly of the reads was done with the unicycler tool version 0.4 .8 at the galaxy website (https://usegalaxy. $\mathrm{eu} /$ ) with exclusion of contigs shorter of one $\mathrm{kb}$ and all other settings set to standard parameters. The assembled genomes were annotated using the NCBI PGAP, rapid annotations using subsystems technology (RAST) [43] and with an inhouse pipeline using the "The institute for Genomic Research" (TIGR) annotation. The average nucleotide indices (ANIb) were calculated with JSpeciesWS version 3.7.8 [44]. The Blast Diagnostic Gene Finder (BADGE) was used to find diagnostic marker genes (DMGs) or unique CDS of the T. halophilus lineages and strains [45]. The predicted proteins of metabolic pathways were checked with pBlast (https://blast. ncbi.nlm.nih.gov/Blast.cgi) and smartBlast (https://blast. ncbi.nlm.nih.gov/smartblast/) from NCBI. Furthermore, 
the CDS search of NCBI (https://www.ncbi.nlm.nih.gov/ Structure/cdd/wrpsb.cgi) was used to check for conserved domains in predicted proteins. Prophages sequences in the genome were predicted with the PHAge Search Tool Enhanced Release (PHASTER) [46]. To check for bacteriocin production cluster the genomes were analyzed with BAGEL4 [33]. CRISPR loci and CAS proteins were identified using Crisprdb (https://crisprcas.i2bc.paris-saclay. fr). The Genome-to-Genome distance calculator ver. 2.1 was used to calculate the relatedness between different strains [47]. Hierarchical clustering of the functional clusters/genes was done with Perseus 1.6.14.0 using the hierarchical clustering function with the distance calculation set to Euclidean distance and the linkage set to average. The maximal number of iterations was set to 1.000 and all clusters/genes pictured in Fig. 3 were used for the distance calculations. All sequence alignments in this study were done in mega7 [48]. Sequences were aligned using Clustal $\omega$ as implemented in mega7. Dendrograms were reconstructed using the neighbor-joining [49] or maximum-likelihood algorithm [50]. To construct the pan/ core genome plot (Figure. S1) based on the amino acid sequences of the strains, CMG biotools 2.2 was used.

\section{Utilization of carbohydrates}

The API 50 CHL (BioMérieux, Marcy l'Etoile, France) was used to identify different fermentation patterns of the isolates. To inoculate a test strip, an overnight culture was grown in MRS or TSA containing $5 \%(\mathrm{w} / \mathrm{v}) \mathrm{NaCl}$. The $\mathrm{OD}_{600 \mathrm{~nm}}$ of this culture was set to 0.3 , washed with full strength Ringer's solution (Merck, Darmstadt, Germany) and resuspended in API 50 CHL medium containing $2 \%(\mathrm{w} / \mathrm{v}) \mathrm{NaCl}$. The test strips were evaluated after an incubation period of $48 \mathrm{~h}$ at $30^{\circ} \mathrm{C}$ (Table 2).

\section{Formation of biogenic amines}

To screen for production of biogenic amines (histamine and tyramine) in the newly isolated T. halophilus strains, the strains were cultivated in a modified MRS medium supplied with $0.005 \%(\mathrm{w} / \mathrm{v})$ pyridoxal 5-phosphate and $10 \mathrm{mM}$ of LHistidine monochloride or L-Tyrosine disodium salt [51]. Cultivation was done in $1 \mathrm{ml}$ medium in $1.5 \mathrm{ml}$ Eppendorf tubes, which were inoculated with a single colony of each strain. The Latilactobacillus sakei TMW 1.1474 and L. curvatus TMW 1.595 were taken as positive control for histamine or tyramine production. The tubes were optically evaluated for a change in color after an incubation time of $48 \mathrm{~h}$ at $30^{\circ} \mathrm{C}$ (Table S3).

\section{Determination of salt tolerance}

Growth of each strain was recorded in MRS pH 5.7 supplied with different $\mathrm{NaCl}$ concentrations, to determine the strain specific optimal $\mathrm{NaCl}$ concentration. Therefore, $50 \mathrm{ml}$ MRS with $2 \%-18 \%(\mathrm{w} / \mathrm{v}) \mathrm{NaCl}$ were inoculated with $500 \mu \mathrm{l}$ of an overnight culture adjusted to an $\mathrm{OD}_{600 \mathrm{~nm}}$ of 0.2 and resuspended in full strength Ringer's solution (Merck, Darmstadt, Germany) and incubated $48 \mathrm{~h}$ at $30{ }^{\circ} \mathrm{C}$ without shaking. The $\mathrm{OD}_{600 \mathrm{~nm}}$ was measured after $48 \mathrm{~h}$ in a SPECTROstan ${ }^{\text {nano }}$ plate reader (BMG, Labtech, Ortenberg, Germany) using a 96 well plate (Sarstedt, Nümbrecht, Germany) (Table 2).

\section{Accession numbers}

The sequenced genomes are available on NCBI with the accession numbers: JACABZ000000000, JACACA000000000, JACACB000000000, JACACH000000000, JACACI000000000, JACACK000000000 and JACTUX000000000.

\section{Supplementary Information}

The online version contains supplementary material available at https://doi. org/10.1186/s12866-021-02381-1.

Additional file 1: Figure S1. Plotted pan-(blue) and core-(red) genome of T.halophilus strain. For every strain added thepan genome increases and the core genome decreases slightly after 17 strains added. Therefore, the core genome is considered as closed after the addition of every strain from this set. 1: DSM 20339 ${ }^{\top}$, 2: DSM 23766 ${ }^{\top}, 3$ : NBRC 12172, 4: NISL 7126, 5: 11, 6: D10, 7: D-86, 8: KG12, 9: YA163, 10:YA5, 11:YG2, 12:WJ7, 13: DSM 20337, 14: NISL 7118, 15: KUD23, 16: MJ4, 17:FBL3, 18: YJ1, 19: TMW 2.2254, 20: TMW 2.2256, 21: TMW 2.2257, 22: TMW 2.2263, 23: TMW 2.2264, 24: TMW 2.2266, 25: 8C7.

Additional file 2: Figure S2. A phylogenetic treeof the 16S rRNA gene sequences of the genus Tetragenococcus with the newlyisolated strains and the respective type strains of each species was constructed using the Neighbor-Joining method [49]. The accession number of the 16S rRNA of the type strains is given in brackets. For the newly isolated strains, the genome accession number is present inbrackets. The optimal tree with the sum of branch length $=0.09391473$ is shown. Bootstrap values (1000 replicates) are shown next to the branches [52]. The tree is drawn to scale, with branchlengths in the same units as those of the evolutionary distances used to inferthe phylogenetic tree. The evolutionary distances were computed using theMaximum Composite Likelihood method [53] and are in the units of the number of base substitutions per site. Allpositions containing gaps and missing data were eliminated. There were a total of 1214 positions in the final dataset. The type strain of Enterococcus faecium DSM $20477^{\top}$ served as outgroup.

Additional file 3: Figure S3. Phylogenetic tree of T. halophilus based on concatenated nucleotide sequences of the housekeeping genes(fus $A$, gyrA, gyrB, lepA, pyrG, recA, rpoD) using the Maximum Likelihood methodbased on the Tamura-Nei model [54]. Thetree with the highest log likelihood (-27635.30) is shown. The percentage oftrees in which the associated taxa clustered together is shown next to thebranches. Initial tree(s) for the heuristic search were obtained automaticallyby applying Neighbor-Join and BioNJ algorithms to a matrix of pairwisedistances estimated using the Maximum Composite Likelihood (MCL) approach, andthen selecting the topology with superior log likelihood value. The tree isdrawn to scale, with branch lengths measured in the number of substitutions persite. All positions containing gaps and missing data were eliminated. Therewere a total of 12057 positions in the final dataset. The strains isolated fromlupine moromi are marked in yellow. T. osmophilus DSM $23765^{\top}$ wasused as an outgroup.

Additional file 4: Table S1. CRISPR/Cas systems and intact prophages detectedin T. halophilus. The CRISPR/Cas sequences were identified using 
the CRISPRdb(https://crisprcas.i2bc.paris-saclay.fr). The evidence level indicates how manymarker proteins of a specific Cas type were found. Strains are ordered byisolation source, Cas type detected and evidence level. The intact prophageswere predicted using PHASTER (https://phaster.ca).

Additional file 5: Table S2. Comparative analysisusing BADGE [45] for the identification CDS specific to lineage I (Table S2 A)or lineage II (Table S2 B). BADGE could also identify some CDS only present insome strains of lineage II (Table S2 C). The Strains of each lineage are shown above and the presence or absence of a highly similar CDS is shown as a"+" or "-" in the respective column.

Additional file 6: Table S3. Formation of biogenic amines was tested as described by Bover-Cid et al. [51] in $1.5 \mathrm{ml}$ Eppendorf tubes.Each strain was cultivated $48 \mathrm{~h}$ at $30^{\circ} \mathrm{C}$ before optical evaluation. TMW 1.1474 and TMW 1.595 were used as positive control. ND, not detected.

\section{Acknowledgements}

We thank Purvegan for providing the koji preparations from lupine seeds.

\section{Authors' contributions}

TL performed all laboratory experiments, performed the genomic analysis and wrote the manuscript. RFV participated in the discussion of the results and helped writing the manuscript. MAE supervised the laboratory experiments, participated in the discussion of the results and helped writing the manuscript. MAE and RFV designed the study. All authors read and approved the final manuscript.

\section{Funding}

Open Access funding enabled and organized by Projekt DEAL. The German Ministry of Food and Agriculture (BMEL) supported part of this work in project. 28-1-A4.001-17.

\section{Availability of data and materials}

All genomes can be accessed at the NCBI website with the respective accession number given in Table 1. All data generated or analyzed during this study are included in this published article and its supplementary files.

\section{Declarations}

\section{Ethics approval and consent to participate}

Not applicable.

\section{Consent for publication}

Not applicable.

\section{Competing interests}

The authors declare that they have no competing interests.

Received: 1 July 2021 Accepted: 3 November 2021

Published online: 20 November 2021

\section{References}

1. Collins MD, Williams AM, Wallbanks $S$. The phylogeny of Aerococcus and Pediococcus as determined by $16 \mathrm{~S}$ rRNA sequence analysis: description of Tetragenococcus gen. nov. FEMS Microbiol Lett. 1990;70:255-62. doi:https://doi.org/10.1111/j.1574-6968.1990.tb14006.x.

2. Satomi M, Kimura B, Mizoi M, Sato T, Fujii T. Tetragenococcus muriaticus sp. nov., a new moderately halophilic lactic acid bacterium isolated from fermented squid liver sauce. Int J Syst Bacteriol. 1997;47:832-6.

3. Lee M, Kim MK, Vancanneyt M, Swings J, Kim SH, Kang MS, et al. Tetragenococcus koreensis sp. nov., a novel rhamnolipid-producing bacterium. Int J Syst Evol Microbiol. 2005;55:1409-13.

4. Ennahar S, Cai Y. Biochemical and genetic evidence for the transfer of Enterococcus solitarius Collins et al. 1989 to the genus Tetragenococcus as Tetragenococcus solitarius comb. nov. Int J Syst Evol Microbiol. 2005:55:589-92.
5. Justé A, Van Trappen S, Verreth C, Cleenwerck I, De Vos P, Lievens B, et al. Characterization of Tetragenococcus strains from sugar thick juice reveals a novel species, Tetragenococcus osmophilus sp. nov., and divides Tetragenococcus halophilus into two subspecies, T. halophilus subsp. halophilus subsp. nov. and T. halophilus subsp. flandriensis subsp. nov. Int J Syst Evol Microbiol. 2012;62:129-37. doi:https://doi.org/10.1099/ijs.0.029157-0.

6. Sakaguchi K. Studies on the activities of bacteria in soy sauce brewing: Part III. Taxonomic studies on Pediococcus soyae nov. Sp., The soy sauce lactic acid bacteria. J Agric Chem Soc Japan. 1958;22:354-62.

7. Justé A, Lievens B, Rediers H, Willems KA. The genus Tetragenococcus. Lact Acid Bact Biodivers Taxon. 2014;9781444333:213-27.

8. Kobayashi T, Kajiwara M, Wahyuni M, Hamada-Sato N, Imada C, Watanabe E. Effect of culture conditions on lactic acid production of Tetragenococcus species. J Appl Microbiol. 2004;96:1215-21. doi:https://doi.org/10. 1111/j.1365-2672.2004.02267.x.

9. Villar M, de Ruiz Holgado AP, Sanchez JJ, Trucco RE, Oliver G. Isolation and characterization of Pediococcus halophilus from salted anchovies (Engraulis anchoita). Appl Environ Microbiol. 1985;49:664-6.

10. Röling WFM, Van Verseveld HW. Characterization of Tetragenococcus halophila populations in Indonesian soy mash (kecap) fermentation. Appl Environ Microbiol. 1996;62:1203-7.

11. Lee JH, Heo S, Jeong K, Lee B, Jeong DW. Genomic insights into the non-histamine production and proteolytic and lipolytic activities of Tetragenococcus halophilus KUD23. FEMS Microbiol Lett. 2018;365:1-4

12. Abe K, Uchida K. Correlation between depression of catabolite control of xylose metabolism and a defect in the phosphoenolpyruvate:mannose phosphotransferase system in Pediococcus halophilus. J Bacteriol. 1989;171:1793-800.

13. Harada R, Yuzuki M, Ito K, Shiga K, Bamba T, Fukusaki E. Influence of yeast and lactic acid bacterium on the constituent profile of soy sauce during fermentation. J Biosci Bioeng. 2017;123:203-8.

14. Lee KE, Lee SM, Choi YH, Hurh BS, Kim Y-S. Comparative volatile profiles in soy sauce according to inoculated microorganisms. Biosci Biotechnol Biochem. 2013;77:2192-200. doi:https://doi.org/10.1271/bbb.130362.

15. Kim KH, Lee SH, Chun BH, Jeong SE, Jeon CO. Tetragenococcus halophilus MJ4 as a starter culture for repressing biogenic amine (cadaverine) formation during saeu-jeot (salted shrimp) fermentation. Food Microbiol. 2019;82 February:465-73. doi:https://doi.org/10.1016/j.fm.2019.02.017.

16. Li J, Huang J, Jin Y, Wu C, Shen D, Zhang S, et al. Aflatoxin B 1 degradation by salt tolerant Tetragenococcus halophilus CGMCC 3792. Food Chem Toxicol. 2018;121:430-6. doi:https://doi.org/10.1016/j.fct.2018.08.063.

17. Robert H, Le Marrec C, Blanco C, Jebbar M. Glycine betaine, carnitine, and choline enhance salinity tolerance and prevent the accumulation of sodium to a level inhibiting growth of Tetragenococcus halophila. Appl Environ Microbiol. 2000;66:509-17.

18. Chun BH, Han DM, Kim KH, Jeong SE, Park D, Jeon CO. Genomic and metabolic features of Tetragenococcus halophilus as revealed by pan-genome and transcriptome analyses. Food Microbiol. 2019;83 April:36-47. doi:https://doi.org/10.1016/j.fm.2019.04.009.

19. Heo S, Lee J, Lee JH, Jeong DW. Genomic Insight into the Salt Tolerance of Enterococcus faecium, Enterococcus faecalis and Tetragenococcus halophiIus. J Microbiol Biotechnol. 2019;29:1591-602.

20. He G, Wu C, Huang J, Zhou R. Effect of exogenous proline on metabolic response of Tetragenococcus halophilus under salt stress. J Microbiol Biotechnol. 2017;27:1681-91.

21. Liu L, Si L, Meng X, Luo L. Comparative transcriptomic analysis reveals novel genes and regulatory mechanisms of Tetragenococcus halophilus in response to salt stress. J Ind Microbiol Biotechnol. 2015;42:601-16.

22. Lin J, Liang H, Yan J, Luo L. The molecular mechanism and post-transcriptional regulation characteristic of Tetragenococcus halophilus acclimation to osmotic stress revealed by quantitative proteomics. J Proteomics. 2017;168 May:1 -14. doi:https://doi.org/10.1016/j.jprot.2017.08.014.

23. Justé A, Lievens B, Frans I, Marsh TL, Klingeberg M, Michiels CW, et al. Genetic and physiological diversity of Tetragenococcus halophilus strains isolated from sugar- and salt-rich environments. Microbiology. 2008:154:2600-10.

24. Uchida M, Miyoshi T, Yoshida G, Niwa K, Mori M, Wakabayashi H. Isolation and characterization of halophilic lactic acid bacteria acting as a starter culture for sauce fermentation of the red alga Nori (Porphyra yezoensis). J Appl Microbiol. 2014;116:1506-20. 
25. Unno R, Matsutani M, Suzuki T, Kodama K, Matsushita H, Yamasato K, et al. Lactic acid bacterial diversity in Brie cheese focusing on salt concentration and $\mathrm{pH}$ of isolation medium and characterisation of halophilic and alkaliphilic lactic acid bacterial isolates. Int Dairy J. 2020;109:104757. doi:https://doi.org/10.1016/j.idairyj.2020.104757.

26. lizuka H, Yamasato K. Pediococcus soyae nov. sp. Main lactic acid bacteria in "Shoyu Moromi “*. J Gen Appl Microbiol. 1959;5:58-73. doi:https://doi. org/10.2323/jgam.5.58.

27. Uchida K. Multiplicity in soy pediococci carbohydrate fermentation and its application for analysis of their flora. J Gen Appl Microbiol. 1982;28:215-23.

28. Kobayashi T, Kimura B, Fujii T. Differentiation of Tetragenococcus populations occurring in products and manufacturing processes of puffer fish ovaries fermented with rice-bran. Int J Food Microbiol. 2000;56:211-8.

29. Kobayashi T, Kajiwara M, Wahyuni M, Kitakado T, Hamada-Sato N, Imada C, et al. Isolation and characterization of halophilic lactic acid bacteria isolated from "terasi" shrimp paste: A traditional fermented seafood product in Indonesia. Journal of General and Applied Microbiology. 2003;49:279-86.

30. Wakinaka T, Watanabe J. Transposition of IS4 Family Insertion Sequences ISTeha3, ISTeha4, and ISTeha5 into the arc Operon Disrupts Arginine Deiminase System in Tetragenococcus halophilus. Appl Environ Microbiol. 2019;85:1-12. doi:https://doi.org/10.1128/AEM.00208-19.

31. Uchida K, Kanbe C. Occurrence of bacteriophages lytic for Pediococcus halophilus, a halophilic lactic-acid bacterium, in soy sauce fermentation. J Gen Appl Microbiol. 1993;39:429-37. doi:https://doi.org/10.2323/ jgam.39.429.

32. Higuchi T, Uchida K, Abe K. Preparation of Phage-insensitive Strains of Tetragenococcus halophila and Its Application for Soy Sauce Fermentation. Bioscience, Biotechnology and Biochemistry. 1999;63:415-7.

33. de Jong A, van Hijum SAFT, Bijlsma JJE, Kok J, Kuipers OP. BAGEL: A webbased bacteriocin genome mining tool. Nucleic Acids Res. 2006;34 WEB. SERV. ISS.:273-9.

34. Tindall BJ, Rosselló-Móra R, Busse HJ, Ludwig W, Kämpfer P. Notes on the characterization of prokaryote strains for taxonomic purposes. Int J Syst Evol Microbiol. 2010;60:249-66.

35. Barco RA, Garrity GM, Scott JJ, Amend JP, Nealson KH, Emerson D. A genus definition for bacteria and archaea based on a standard genome relatedness index. MBio. 2020;11:1-20.

36. Inglin RC, Meile L, Stevens MJA. Clustering of Pan- and Core-genome of Lactobacillus provides Novel Evolutionary Insights for Differentiation. BMC Genomics. 2018;19:1-15.

37. Sakamoto T, Nishimura Y, Makino Y, Sunagawa Y, Harada N. Biochemical characterization of a GH53 endo- $\beta$-1,4-galactanase and a GH35 exo- $\beta$ 1,4-galactanase from Penicillium chrysogenum. Appl Microbiol Biotechnol. 2013;97:2895-906.

38. Matsudo T, Aoki T, Abe K, Fukuta N, Higuchi T, Sasaki M, et al. Determination of Ethyl Carbamate in Soy Sauce and Its Possible Precursor. J Agric Food Chem. 1993;41:352-6.

39. Garneau JE, Moineau S. Bacteriophages of lactic acid bacteria and their impact on milk fermentations. Microb Cell Fact. 2011;10 SUPPL. 1:S20. doi:https://doi.org/10.1186/1475-2859-10-S1-S20.
40. Rogalski E, Vogel RF, Ehrmann MA. Monitoring of Lactobacillus sanfranciscensis strains during wheat and rye sourdough fermentations by CRISPR locus length polymorphism PCR. Int J Food Microbiol. 2020;316:108475. doi:https://doi.org/10.1016/j.ijfoodmicro.2019.108475.

41. Lülf R, Vogel RF, Ehrmann MA. Microbiota dynamics and volatile compounds in lupine based Moromi fermented at different salt concentrations. Int J Food Microbiol. 2021;354:109316. https://doi.org/10.1016/j. ijfoodmicro.2021.109316.

42. De man JC, Rogosa M, Sharpe ME. A medium for the cultivation of Lactobacilli. J Appl Bacteriol. 1960;23:130-5. doi:https://doi.org/10.1111/j. 1365-2672.1960.tb00188.x.

43. Aziz RK, Bartels D, Best A, DeJongh M, Disz T, Edwards RA, et al. The RAST Server: Rapid annotations using subsystems technology. BMC Genomics. 2008:9:1-15.

44. Richter M, Rosselló-Móra R, Oliver Glöckner F, Peplies J. JSpeciesWS: a web server for prokaryotic species circumscription based on pairwise genome comparison. Bioinformatics. 2016;32:929-31. doi:https://doi.org/10.1093/ bioinformatics/btv681.

45. Behr J, Geissler AJ, Schmid J, Zehe A, Vogel RF. The identification of novel diagnostic marker genes for the detection of beer spoiling Pediococcus damnosus strains using the BIAst diagnostic gene findEr. PLoS One. 2016;11:1-23.

46. Arndt D, Grant JR, Marcu A, Sajed T, Pon A, Liang Y, et al. PHASTER: a better, faster version of the PHAST phage search tool. Nucleic Acids Res. 2016;44:W16-21. doi:https://doi.org/10.1093/nar/gkw387.

47. Meier-Kolthoff JP, Auch AF, Klenk HP, Göker M. Genome sequence-based species delimitation with confidence intervals and improved distance functions. BMC Bioinformatics. 2013;14.

48. Kumar S, Stecher G, Tamura K. MEGA7: Molecular Evolutionary Genetics Analysis Version 7.0 for Bigger Datasets. Mol Biol Evol. 2016;33:1870-4.

49. Saitou N, Nei M. The neighbor-joining method: a new method for reconstructing phylogenetic trees. Mol Biol Evol. 1987;4:406-25.

50. Felsenstein J. Evolutionary trees from DNA sequences: A maximum likelihood approach. J Mol Evol. 1981;17:368-76.

51. Bover-Cid S, Holzapfel WH. Improved screening procedure for biogenic amine production by lactic acid bacteria. Int J Food Microbiol. 1999;53:33-41. doi:https://doi.org/10.1016/s0168-1605(99)00152-x.

52. Felsenstein J. Confidence Limits on Phylogenies: an Approach Using the Bootstrap. Evolution (N Y). 1985;39:783-91.

53. Tamura K, Nei M, Kumar S. Prospects for inferring very large phylogenies by using the neighbor-joining method. Proc Natl Acad Sci U S A. 2004;101:11030-5.

54. Tamura K, Nei M. Estimation of the number of nucleotide substitutions in the control region of mitochondrial DNA in humans and chimpanzees. Mol Biol Evol. 1993;10:512-26.

\section{Publisher's Note}

Springer Nature remains neutral with regard to jurisdictional claims in published maps and institutional affiliations.

\footnotetext{
Ready to submit your research? Choose BMC and benefit from:

- fast, convenient online submission

- thorough peer review by experienced researchers in your field

- rapid publication on acceptance

- support for research data, including large and complex data types

- gold Open Access which fosters wider collaboration and increased citations

- maximum visibility for your research: over $100 \mathrm{M}$ website views per year
}

At BMC, research is always in progress.

Learn more biomedcentral.com/submissions 